\title{
The Clinical and Hormonal Characteristics of Primary Adrenal Lymphomas: The Necessity of Early Detection of Adrenal Insufficiency
}

\author{
Ko Harada ${ }^{1}$, Kosuke Kimura ${ }^{1}$, Masaya Iwamuro ${ }^{1}$, Tomohiro Terasaka ${ }^{1}$, \\ Yoshihisa Hanayama ${ }^{1}$, Eisei Kondo ${ }^{1}$, Eiko Hayashi ${ }^{2}$, Tadashi Yoshino ${ }^{2}$ and Fumio Otsuka ${ }^{1}$
}

\begin{abstract}
:
Objective To analyze the clinical and endocrine characteristics of patients with primary adrenal lymphoma.

Patients We retrospectively reviewed the cases of five patients with primary adrenal lymphoma who were treated in our hospital between April 2004 and March 2015. We investigated the characteristics of the clinical and pathological findings, treatment, prognosis and complications of adrenal insufficiency.

Results Adrenal insufficiency, which was confirmed by the laboratory data at the initial presentation, was observed in two cases. One case was complicated by relative adrenal insufficiency during a course of chemotherapy. The plasma adrenaline and urinary adrenaline levels were decreased in four cases and three cases, respectively. Diffusion MRI was radiologically diagnostic. In all of the cases, the patients were pathologically diagnosed with diffuse large-B cell lymphoma and were treated with rituximab and CHOP (cyclophosphamide, doxorubicin, vincristine and prednisone)-like chemotherapy. Two patients received central nervous system prophylaxis with high-dose methotrexate. Four of the patients survived and one patient died during the follow-up period.

Conclusion The early detection of adrenal insufficiency and the administration of an appropriate dose of hydrocortisone are necessary during the course of chemotherapy as well as at the initial manifestation. The exclusion of adrenal dysfunction prior to invasive diagnostic procedures, such as CT-guided needle biopsy, is also critical.
\end{abstract}

Key words: adrenocortical insufficiency, adrenal tumor, diffuse large B-cell lymphoma, primary adrenal lymphoma

(Intern Med 56: 2261-2269, 2017)

(DOI: 10.2169/internalmedicine.8216-16)

\section{Introduction}

Non-Hodgkin lymphoma (NHL) arising in the endocrine system accounts for only 3\% of extranodal malignant lymphomas, and primary adrenal lymphoma (PAL) accounts for only $0.2 \%$ of those lymphomas (1). The prognosis is generally considered to be poor, partly due to a high frequency of central nervous system (CNS) invasion in comparison to other lymphomas $(2,3)$. Due to the rarity of the disease in Japan, its clinical and imaging features and its treatment, in- cluding CNS prophylaxis, have not been fully established (4).

A previous study showed that $61 \%$ of patients with PAL had adrenal insufficiency and that adrenal insufficiency is a prognostic factor for PAL (4). However, the management of adrenal insufficiency at presentation or during the course of chemotherapy has rarely been discussed. We analyzed the clinical characteristics of five patients with PAL who were treated in our hospital and herein discuss the need for endocrinological management for co-existing adrenal insufficiency due to PAL.

${ }^{1}$ Department of General Medicine, Okayama University Graduate School of Medicine, Dentistry and Pharmaceutical Sciences, Japan and ${ }^{2}$ Department of Pathology, Okayama University Graduate School of Medicine, Dentistry and Pharmaceutical Sciences, Japan Received: September 2, 2016; Accepted: January 24, 2017; Advance Publication by J-STAGE: August 10, 2017 Correspondence to Dr. Ko Harada, me422084@s.okayama-u.ac.jp 
Table 1. Clinical Profile of 5 Cases of PAL.

\begin{tabular}{|c|c|c|c|c|c|c|c|}
\hline $\begin{array}{l}\text { Case } \\
\text { No. }\end{array}$ & $\begin{array}{l}\text { Age } \\
\text { (year) }\end{array}$ & $\begin{array}{l}\text { Gender } \\
(\mathrm{M} / \mathrm{F})\end{array}$ & Manifestation & Laterality & $\begin{array}{c}\mathrm{LDH}(\mathrm{IU} / \mathrm{L}) \\
{[120-240]}\end{array}$ & $\begin{array}{c}\text { sIL-2R }(\mathrm{U} / \mathrm{mL}) \\
{[122-496]}\end{array}$ & IPI \\
\hline 1 & 82 & M & fatigue, loss of appetite, weight loss & bilateral & 249 & 2,086 & high \\
\hline 2 & 49 & M & fatigue, loss of appetite, pigmentation & bilateral & 253 & 971 & high intermediate \\
\hline 3 & 41 & M & right flank pain & right & 242 & 1,091 & high intermediate \\
\hline 4 & 71 & M & by chance abdominal US & bilateral & 918 & 1,604 & high intermediate \\
\hline 5 & 72 & $\mathrm{~F}$ & by chance $\mathrm{CT}$ & bilateral & 203 & 882 & high \\
\hline
\end{tabular}

LDH: lactate dehydrogenase, sIL-2R: soluble interleukin-2 receptor, IPI: international prognostic index, M: male, F: female, US: ultrasonography, CT: computed tomography, [normal range]

Table 2. Histological Assessment of PAL.

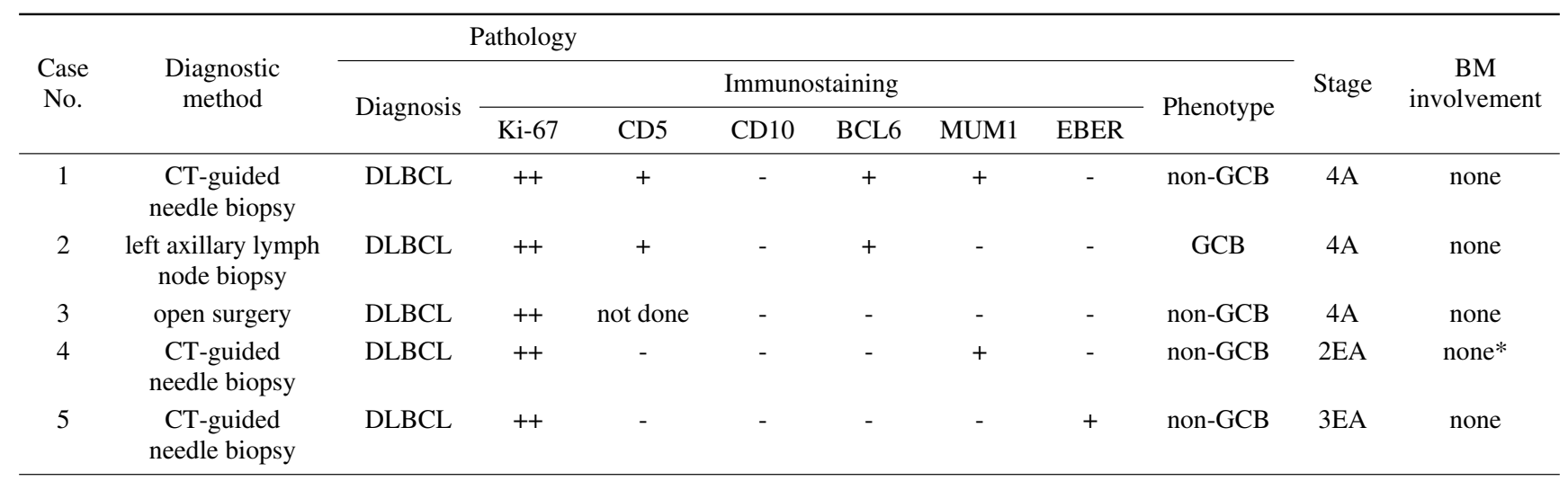

BM involvement: bone marrow involvement, DLBCL: diffuse large-B cell lymphoma, EBER: Epstein-Barr virus-encoded small RNA, GCB: germinal center B-cell-like, +: positive, ++: highly positive, -: negative

*Bone marrow biopsy was not performed because ${ }^{18} \mathrm{~F}$-fluorodeoxyglucose positron emission tomography-computed tomography revealed no evidence of bone marrow involvement

\section{Materials and Methods}

Five patients were diagnosed with PAL in our hospital between April 2004 and March 2015. We retrospectively investigated the demographic information, clinical and pathological findings, treatment, prognosis and the complication of adrenal insufficiency in these five cases. Since there was no strict definition for PAL, we used the following definition that has been agreed upon by the majority of experts: no history of lymphoma elsewhere in the body, and adrenal lesions that were unequivocally dominant if lymph nodes or other organs were involved (4). This definition suggests that the adrenal lesion was the primary tumor in all of our cases. Adrenal insufficiency was diagnosed on the basis of clinical symptoms, such as hypotension, hyponatremia, hypoglycemia and pigmentation, and the laboratory data of the serum cortisol levels and plasma adrenocorticotropic hormone (ACTH) levels. The serum cortisol levels and plasma ACTH levels were measured early in the morning with the patient at rest. This study was approved by the Ethical Committee of Okayama University Hospital and adhered to the Declaration of Helsinki (No. 1507-029).

\section{Results}

\section{The profiling of PAL patients}

The patients' characteristics, manifestations and laboratory data are shown in Table 1. The patients included four men and one woman. The median age at the diagnosis was 71 years (range, 41-82 years). The patients presented with fatigue and weight loss (Cases 1 and 2), and right flank pain (Case 3). The adrenal tumors in the other two patients were incidentally found by computed tomography (CT) or abdominal echography. Four patients (Cases 1, 2, 4 and 5) had bilateral lesions. With the exception of one patient (Case 4) the serum lactate dehydrogenase (LDH) levels of all patients were slightly elevated, with a median level of 249 IU/L (range, 203-918 IU/L). The level of soluble interleukin-2 receptor (sIL-2R) was elevated in all patients, with a median level of 1,091 U/mL (range, 882-2,086 U/mL). Two patients (Cases 1 and 5) were classified as high-risk, while three (Cases 2, 3 and 4) were classified as high-intermediate-risk according to the International Prognostic Index (5).

\section{Histological assessment}

The diagnostic methods and pathological findings are shown in Table 2. The diagnostic methods included CT- 
Table 3. Radiological Findings of PAL.

\begin{tabular}{|c|c|c|c|c|c|}
\hline \multirow{2}{*}{$\begin{array}{l}\text { Case } \\
\text { No. }\end{array}$} & \multicolumn{3}{|c|}{ CT } & \multirow{2}{*}{ MRI } & \multirow{2}{*}{$\begin{array}{l}\text { PET-CT } \\
\text { SUV max }\end{array}$} \\
\hline & Tumor size & $\mathrm{LN}$ & Findings & & \\
\hline 1 & $82 \times 52 \mathrm{~mm}$ & paraaortic LN & $\begin{array}{l}\text { homogeneous, } \\
\text { no enhancement }\end{array}$ & $\begin{array}{l}\text { T2WI; same intensity as that of } \\
\text { renal parenchyma, DWI ; high }\end{array}$ & not done \\
\hline 2 & $22 \times 17 \mathrm{~mm}$ & multiple LN & $\begin{array}{l}\text { homogeneous, } \\
\text { no enhancement }\end{array}$ & not done & 31.4 \\
\hline 3 & $88 \times 73 \mathrm{~mm}$ & $\begin{array}{l}\text { hepatic } \\
\text { invasion }\end{array}$ & $\begin{array}{l}\text { heterogenous, } \\
\text { slight enhancement }\end{array}$ & $\begin{array}{l}\text { T2WI; heterogenously high, } \\
\text { DWI; high }\end{array}$ & 38.6 \\
\hline 4 & $83 \times 65 \mathrm{~mm}$ & $\begin{array}{l}\text { splenic } \\
\text { invasion }\end{array}$ & $\begin{array}{l}\text { heterogenous, } \\
\text { slight enhancement }\end{array}$ & $\begin{array}{l}\text { T2WI; heterogenously high, } \\
\text { DWI; high }\end{array}$ & 18.8 \\
\hline 5 & $44 \times 24 \mathrm{~mm}$ & right atrium & $\begin{array}{l}\text { homogenous, } \\
\text { no enhancement }\end{array}$ & not done & 24.7 \\
\hline
\end{tabular}

MRI: magnetic resonance imaging, PET-CT: positron emission tomography-computed tomography, LN: lymph node, SUV: standardized uptake values, T2WI: T2-weighted imaging, DWI: diffusion-weighted imaging

guided needle biopsy of the adrenal tumor in three cases (Cases 1, 4 and 5). Left axillary lymph node biopsy was performed in Case 2. Surgical resection of the right adrenal tumor and right lobe of the liver was performed in Case 3 because a malignant adrenal tumor and its hepatic invasion were suspected based on the imaging findings. All of our patients were pathologically diagnosed with diffuse large-B cell lymphoma (DLBCL). Immunostaining revealed CD5 positivity in two of the five patients (Cases 1 and 2), while all patients were Ki-67-positive. Ki-67 positivity of $>10 \%$ was defined as highly positive. Immunostaining of EpsteinBarr virus-encoded small RNA was positive in one case (Case 5). DLBCLs were ontogenically sub-classified as germinal center B-cell-like (GCB) and non-GCB by immunohistochemistry using the Hans algorithm (6). One case (Case 2) was classified as GCB, while the other 4 cases (Cases 1, 3, 4 and 5) were classified as non-GCB.

\section{The radiological findings}

The radiological findings are shown in Table 3. The mean maximum diameter of the tumors at the diagnosis was 64 $\mathrm{mm}$ (range, 22-88 mm). Imaging studies revealed other lymphoma lesions, including paraaortic lymph nodes (LN) in Case 1 and the involvement of multiple LNs, including bilateral deep jugular LN, paracarina LN, paraesophageal LN and paraaortic LN in Case 2. Hepatic invasion and splenic invasion were seen in Cases 3 and 4, respectively. Enhanced CT was performed in all cases. In Cases 1, 2 and 5, the tumor was homogeneous, without any enhancement, while it was heterogeneous with slight enhancement in Cases 3 and 4. Magnetic resonance imaging (MRI) of the abdomen was performed in three cases (Cases 1, 3 and 4). T1-weighted imaging showed a signal intensity lower than that of the liver. T2-weighted imaging (T2WI) showed almost the same intensity as that of the renal parenchyma in Case 1 and heterogeneous hyperintensity in Cases 3 and 4 (Fig. 1). Diffusion-weighted imaging (DWI) showed a region of high intensity in all 3 cases (Fig. 1). ${ }^{18} \mathrm{~F}$-fluorodeoxyglucose (FDG) positron emission tomography (PET)/CT was performed in four cases (Cases 2-5) (Fig. 2). The uptake of
FDG was confirmed in all cases, and the maximum standardized uptake values (SUV max) were generally high (18.8-38.6; median, 28.0).

\section{Endocrinological assessment}

The adrenal function was evaluated in all patients. The results are shown in Table 4. Three of the five patients had symptoms related to adrenal insufficiency, with fatigue and appetite loss being the major symptoms. With regard to specific symptoms, one patient showed skin pigmentation and another showed hypotension during chemotherapy due to relative adrenocortical insufficiency. In terms of the adrenocortical function, the median serum cortisol level and median plasma ACTH level early in the morning were $8.7 \mu \mathrm{g} /$ $\mathrm{dL}$ (range, 2.3-19.1 $\mu \mathrm{g} / \mathrm{dL}$ ) and $51.1 \mathrm{pg} / \mathrm{mL}$ (range, 10.4-457 $\mathrm{pg} / \mathrm{mL}$ ), respectively. The median 24-hour urinary free cortisol level was $86.4 \mu \mathrm{g} /$ day (range, 50.5-183 $\mu \mathrm{g} /$ day). All of the patients received hormone replacement therapy. Two of the patients (Cases 1 and 2) showed adrenocortical insufficiency, which was confirmed by the laboratory data at the initial presentation. One patient (Case 4) experienced the complication of relative adrenal insufficiency during a course of chemotherapy. For the assessment of the adrenomedullar function, the plasma levels of catecholamines, including adrenaline, noradrenaline and dopamine, and urine adrenaline were measured in all cases. The plasma adrenaline level was less than $0.01 \mathrm{ng} / \mathrm{mL}$ in four cases (Cases 1, 2, 3 and 5), and the urinary adrenaline level was below the normal range in three cases (Cases 1, 2 and 5).

\section{The therapeutic regimen and outcome}

The treatments and clinical outcomes are shown in Table 5. Four patients (Cases 2-5) were treated with rituximab and the CHOP regimen, including cyclophosphamide, doxorubicin, vincristine and prednisone. One patient (Case 1) was initially treated with the CHOP-like regimen and experienced early relapse, which was treated with heavy-ion therapy. One patient (Case 3) was transferred to another hospital and died without any response to chemotherapy. We administered CNS prophylaxis with intrathecal chemotherapy (IT) 


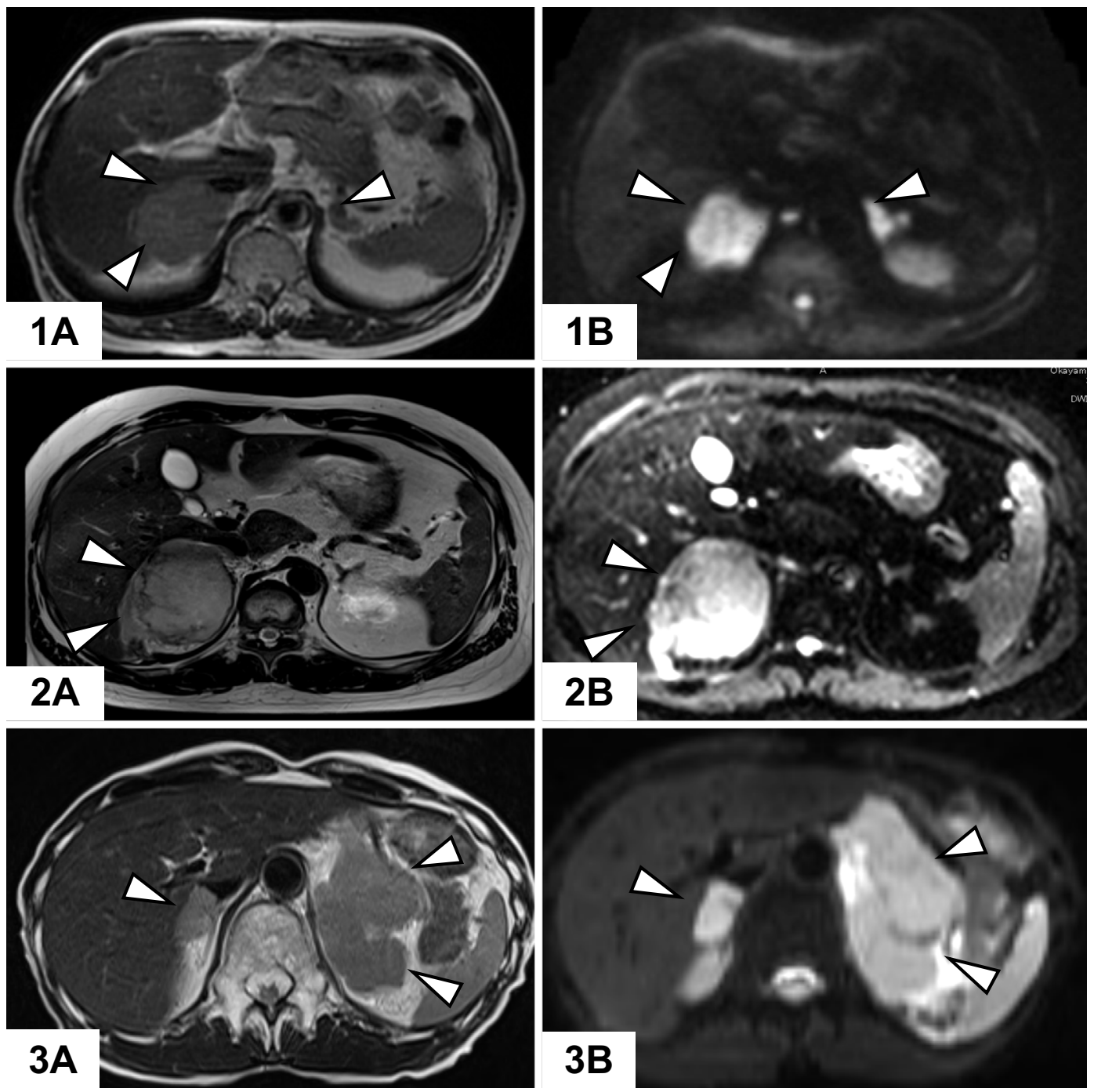

Figure 1. The adrenal MRI findings of PAL. MRI of the abdomen was performed in Cases 1 (1A1B), 3 (2A-2B) and 4 (3A-3B). T2-weighted imaging revealed that the intensity was almost the same as that of the renal parenchyma in one case (1A; arrows). Heterogeneous hyperintensity was observed in the other two cases (2A and 3A; arrows). Diffusion-weighted imaging (DWI) showed high intensity in all 3 cases (1B, 2B and 3B; arrows).

and high-dose methotrexate (HD-MTX) to two patients (Case 2 and 4). Two patients (Case 1 and 3) were treated in other hospitals without receiving CNS prophylaxis. CNS prophylaxis could not be administered to one patient (Case 5) because of pancytopenia and a decreased renal function and due to the anatomical difficulty of performing lumbar puncture. The mean follow-up period was 29 months (range, 6-65 months). Four of the patients survived and one patient died during the follow-up period.

\section{A case presentation}

Case 4 did not show adrenal insufficiency at presentation. However, the patient was considered to be at risk of adrenal insufficiency because he had bilateral adrenal lesions. Thus, we carefully observed his symptoms, vital signs and laboratory data during his hospitalization. On day six of the third course of R-CHOP chemotherapy, the patient showed general fatigue and hypotension (blood pressure, 80/48 $\mathrm{mmHg}$ ).
The patient's serum cortisol level was decreased $(1.4 \mu \mathrm{g} / \mathrm{dL})$. His symptoms improved after the administration of hydrocortisone $(10 \mathrm{mg})$ for adrenal insufficiency. Hydrocortisone treatment was continued until the end of 6 courses of RCHOP chemotherapy. Thereafter, the patient did not experience symptoms of adrenal insufficiency. A diurnal variation test and a corticotropin-releasing hormone (CRH) stimulation test (Fig. 3) were performed after confirming a complete response to chemotherapy. Since the patient's ACTH secretion was almost normal (-2-fold increase) but the cortisol increase was still weak in response to an injection of CRH (0.1 mg), the administration of a lower dose of hydrocortisone (5 mg/day) was continued.

\section{Discussion}

PAL is a very rare type of extranodal lymphoma. Fewer than 200 cases have been described in the medical litera- 


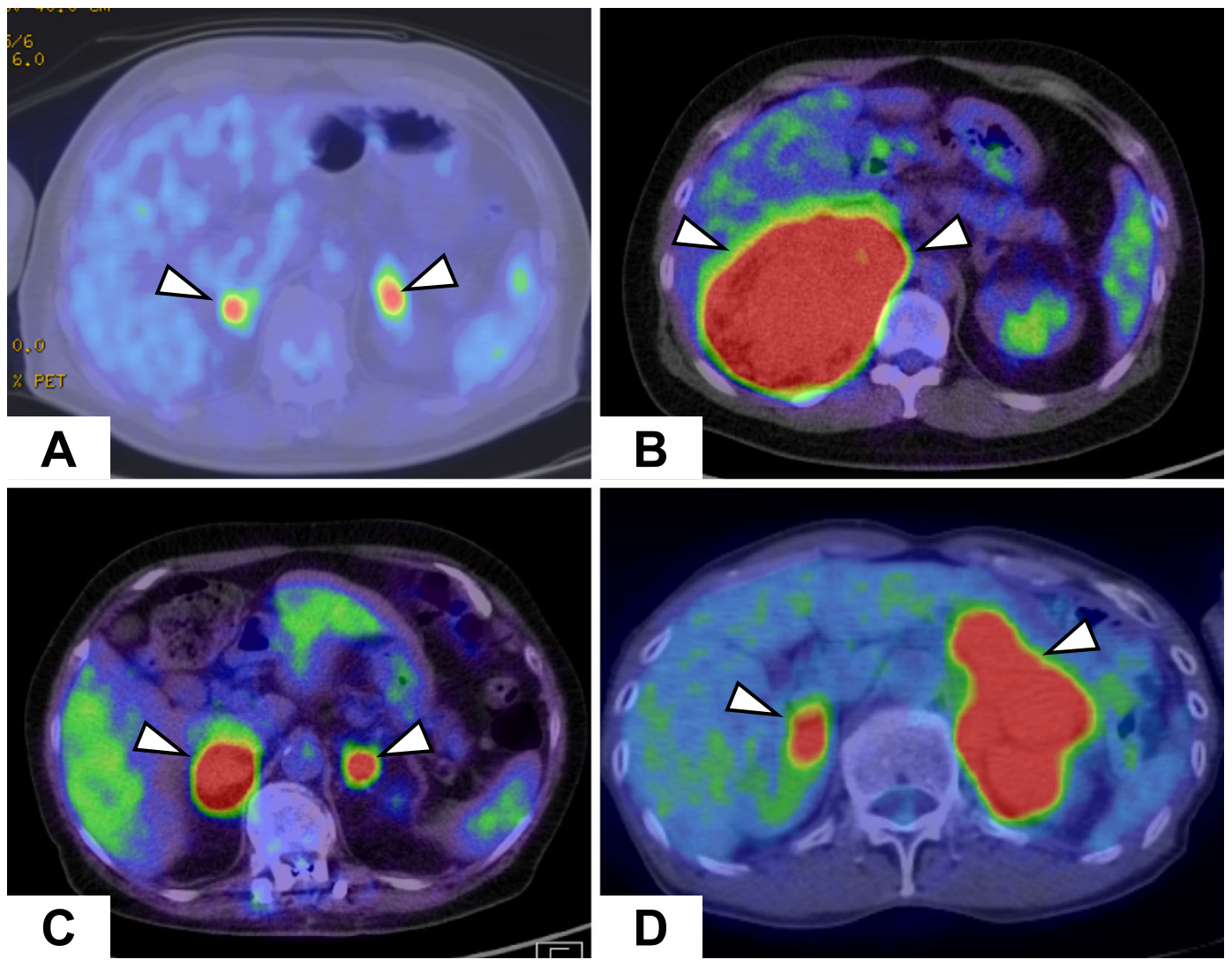

Figure 2. The findings of an FDG-PET scan. ${ }^{18} \mathrm{~F}$-fluorodeoxyglucose (FDG) positron emission tomography/CT was performed in Cases 2 (A, arrows), 3 (B, arrows), 4 (C, arrows) and 5 (D, arrows). The uptake of FDG was confirmed in all cases, and the maximum standardized uptake values (SUV max) were generally high (18.8-38.6; median, 28.0).

ture (7). The male-to-female ratio is 3:1 (average age, approximately 70 years) (7-10). The characteristics of our cases are compatible with those of previous reports (7-10). The clinical manifestations of PAL are generally considered to be B-symptoms, including fever, weight loss and night sweat (4). Other common manifestations include pain and fatigue (4). However, in the present study, only two patients presented with fatigue and weight loss; the other three did not have any symptoms.

Rashidi et al. analyzed the prognostic factors of PAL and revealed that adrenal insufficiency was associated with significantly worse outcomes (4). They also reported that incidence of adrenal insufficiency in PAL patients is $61 \%$, which is higher in comparison to most metastatic cancers of the adrenal glands other than lymphoma (21-33\% in bilateral cases) $(11,12)$. In addition, previous studies revealed that the frequency of adrenal insufficiency in bilateral PAL was higher than that in unilateral PAL (13-15). Four of our patients had bilateral lesions. Three patients with bilateral PAL experienced adrenal insufficiency during their disease course; the other two patients did not. The patients with adrenal insufficiency were treated with hydrocortisone $(10 \mathrm{mg}$ per day) or with a combination of hydrocortisone and fludrocortisone or a combination of hydrocortisone and dexamethasone (16). Hydrocortisone (10 mg) was prescribed for "sick days" in addition to a basic dose of a corticoster- oid (17).

One patient (Case 4) experienced relative adrenal insufficiency during a course of chemotherapy. This case suggests that even if the adrenal function is normal at the initial presentation, PAL can be complicated by adrenal insufficiency during the course of chemotherapy. Thus, careful observation of symptoms suggesting adrenal insufficiency, including pigmentation, general fatigue and hypotension, and laboratory data such as hyponatremia and hypoglycemia is essential for the early detection of the condition.

Considering that high-dose corticosteroid treatment is used for chemotherapy in cases of PAL, it is possible that secondary adrenal insufficiency occurred due to the administration of high doses of corticosteroids in this case. However, it has been reported that-in most cases-secondary adrenal insufficiency is caused by the administration of corticosteroids for more than three weeks; however, this varies from person to person (18). Since corticosteroids are administered for 5 days in each course of R-CHOP chemotherapy, secondary adrenal insufficiency is considered to be unlikely. In addition, it has been reported that the adrenal function in children who received treatment, including high-dose prednisone or dexamethasone, completely recovered within 10 weeks (19). Considering that hydrocortisone therapy was necessary after chemotherapy in Case 4, adrenal insufficiency due to R-CHOP chemotherapy is unlikely. 


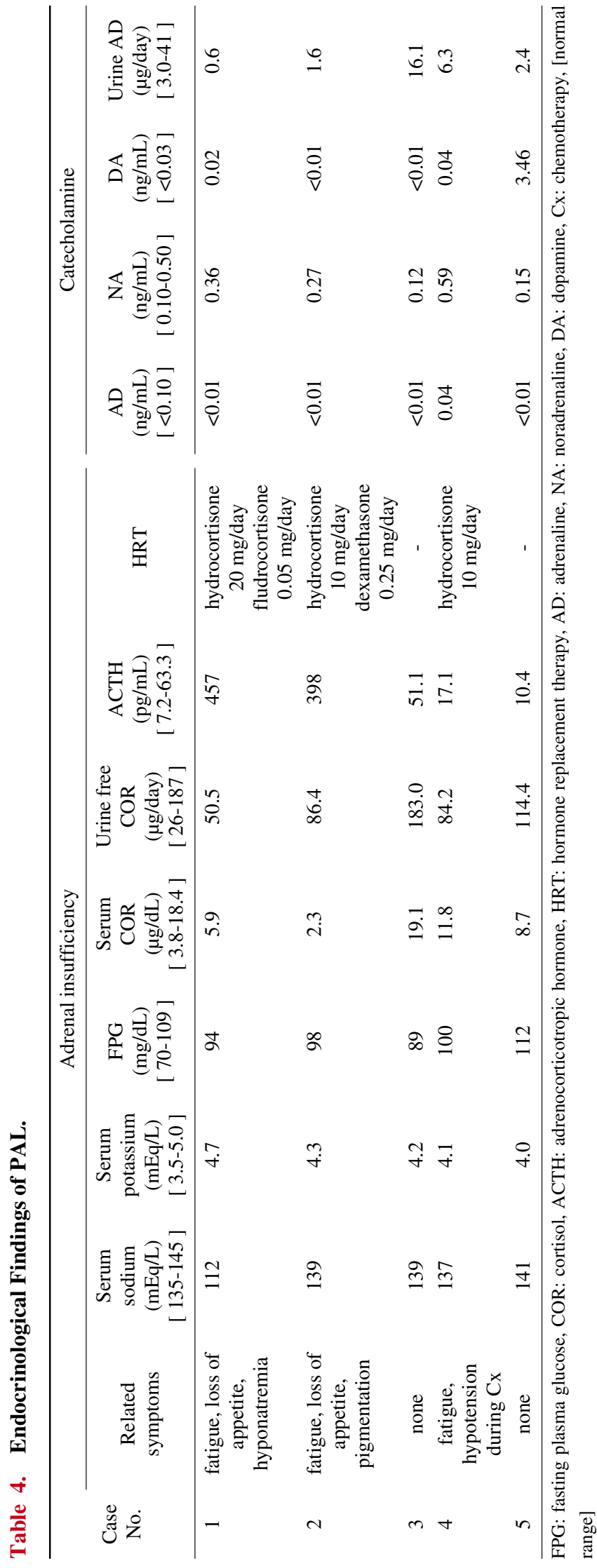

The association between PAL and the adrenomedullar function has rarely been discussed (4). Considering that four of our five patients had a decreased level of plasma adrenaline and that three of them had a decreased level of urinary adrenaline, PAL might be associated with adrenomedullar dysfunction. However, none of our patients showed signs or symptoms of adrenomedullar dysfunction, such as orthostatic hypotension or hypoglycemia (20). The exact mechanism underlying the development of adrenal insufficiency in PAL is still unknown (4). One hypothesis is that a tumor overgrows and finally compresses or replaces the normally functioning adrenal parenchyma or compromises the regional vascular supply to the gland $(11,12)$. Another hypothesis is that adrenal insufficiency is caused by the cytokine-driven, functional paracrine effect that lymphoma cells have in the microenvironment of the adrenal gland (4). This hypothesis might explain the relatively high frequency of adrenal insufficiency in PAL in comparison to other adrenal neoplasms. More research is needed to reveal the exact mechanism underlying the development of adrenal insufficiency in PAL.

The remission of lymphoma did not induce the recovery of the adrenal function in three of our patients who experienced adrenal insufficiency. This may be due to the long period of hormone replacement therapy for adrenal insufficiency or the impaired production of adrenal steroids due to the above-described mechanism. From this point of view, hormone replacement therapy should be continued for the life of the patient. In addition, education about the management of sickness and carrying an emergency card are essential for the prevention and rapid treatment of adrenal crisis (21).

A biopsy is necessary for the diagnosis and classification of NHL. Lymph node excisional biopsy should be considered if one or more enlarged peripheral lymph nodes are present $(22,23)$. If no enlarged lymph nodes are available for biopsy when PAL is suspected, the performance of CTguided needle biopsy of the adrenal gland would be the diagnostic procedure of choice. The differential diagnosis of PAL includes adrenocortical carcinoma, pheochromocytoma and metastatic adrenal cancer (24). CT-guided needle biopsy enables an adrenal tumor to be distinguished from a metastatic tumor (25). The risks of needle biopsy include tumor recurrence along the needle track $(26,27)$. Also, CT-guided needle biopsy should only be performed after excluding pheochromocytoma with biochemical testing, because it may result in hemorrhage and hypertensive crisis (28). Furthermore, if PAL is complicated with adrenal insufficiency, a diagnostic procedure including CT-guided needle biopsy or lymph node biopsy should be performed after the adrenal insufficiency has been treated with an appropriate dose of corticosteroids. This is because these invasive procedures might induce relative adrenal insufficiency (29). In our cases, after confirming that the plasma levels of adrenaline and noradrenaline, and the urinary level of adrenaline were within normal limits and that adrenal insufficiency was well controlled by hormone replacement therapy, we performed CT-guided needle biopsy in 3 cases. Thus, the exclusion of a catecholamine excess state and adrenal insufficiency before the procedure is essential if PAL is clinically suspected.

The CT imaging features of PAL have not been estab- 
Table 5. Therapeutic Regimen and Outcome.

\begin{tabular}{|c|c|c|c|c|c|}
\hline \multirow{2}{*}{$\begin{array}{l}\text { Case } \\
\text { No. }\end{array}$} & \multicolumn{2}{|c|}{ Treatment } & \multicolumn{3}{|c|}{ Response to treatment } \\
\hline & Chemotherapy & CNS prophylaxis & Response & follow-up period (months) & Prognosis \\
\hline 1 & $\begin{array}{l}\text { R-CHOP likex6 } \\
\text { heavy-ion therapy }\end{array}$ & - & $\begin{array}{c}\text { PD } \\
\mathrm{CR} \rightarrow \text { relapse free }\end{array}$ & 38 & alive \\
\hline 2 & R-CHOP×6 & IT, HD-MTX×2 & $\mathrm{CR}$ & 65 & alive \\
\hline 3 & R-CHOP like $\times 6$ & - & PD & 6 & dead \\
\hline 4 & $\mathrm{R}-\mathrm{CHOP} \times 6$ & IT, HD-MTX×2 & $\mathrm{CR}$ & 18 & alive \\
\hline 5 & $\mathrm{R}-\mathrm{CHOP} \times 6$ & - & CR & 18 & alive \\
\hline
\end{tabular}

CNS: central nervous system, R-CHOP: rituximab, cyclophosphamide, doxorubicin, vincristine and prednisone, IT: intrathecal chemotherapy, HD-MTX: high-dose methotrexate, CR: complete response, PD: progressive disease

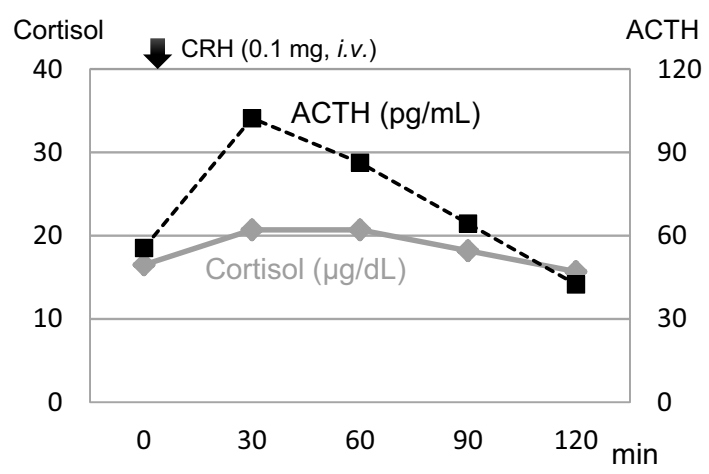

Figure 3. The evaluation of the adrenocortical function by a corticotropin-releasing hormone (CRH) test. In Case 4, the responsiveness of adrenocorticotropic hormone (ACTH) was preserved but that of cortisol was impaired in response to a CRH stimulation test after a series of chemotherapy treatments.

lished $(5,30,31)$. Adrenal lymphoma may appear as discrete masses or show more diffuse involvement of the gland while the shape of the gland may be maintained (30). Although there were no specific findings for PAL in the CT images of our cases, the tumors were not strongly enhanced, which might be important for the differential diagnosis of adrenal tumors such as adrenal adenoma or pheochromocytoma $(32,33)$. On MRI, the signal intensity of PAL is lower than that of the liver on T1-weighted images, while it is typically heterogeneously hyperintense on T2-weighted images $(7,10,30)$. In our cases, these features were compatible with previous reports. The typical findings of PAL on DWI have not been established (4); however, lymphoma usually displays high signal intensity on DWI, as was previously reported for CNS lymphoma (34). Considering that three of our cases showed a high signal intensity on DWI, this might also be a characteristic MRI finding of PAL.

Previous studies revealed that DLBCL, which accounts for $86 \%$ of PAL cases, is the most common histological type of PAL; the other types include intravascular large Bcell lymphoma, anaplastic large cell lymphoma, peripheral T-cell lymphoma, and extranodal NK/T cell lymphoma, nasal type $(14,15,35)$. All of our cases were pathologically diagnosed as having DLBCL. CD5-positivity has been reported in 9\% of DLBCL cases and is reported to be an indi- cator of a poor prognosis and frequent CNS relapse in patients receiving R-CHOP therapy $(36,37)$. Forty percent of our patients had CD5-positive PAL. Thus, the high frequency of CD5 positivity might contribute to the poor prognosis of patients with PAL.

Hans et al. showed that an immunohistochemical panel of CD10, BCL6, and MUM1 was able to classify DLBCL into GCB and non-GCB subgroups with a prognostic significance that was equivalent to that of gene expression profiling (6). According to the Han's algorithm, $80 \%$ of our cases were classified as the non-GCB subtype. Considering that it was previously reported that most PAL cases were subclassified as non-GCB, the pathological characteristics of our cases are compatible with those of previously reported cases $(2,38,39)$. In addition, it was reported that the nonGCB subtype was associated with significantly lower survival in comparison to the GCB subtype (40). These findings suggest that the poor prognosis of PAL might be related to the high prevalence of the non-GCB subtype.

Secondary CNS involvement has been reported to occur in $2-10 \%$ of DLBCL cases and is associated with a poor prognosis $(4,41,42)$. A recent study showed that the risk of CNS relapse was high in patients with PAL $(8,43)$. It has also been reported that HD-MTX as CNS prophylaxis can decrease the risk of CNS recurrence in high-risk DLBCL patients (44). Because the adrenal gland is a high-risk organ for CNS involvement, all of our patients were considered to be candidates for CNS prophylaxis $(45,46)$. Thus, HDMTX was administered to all of the patients who were treated in our hospital unless treatment was contraindicated. We administered CNS prophylaxis with HD-MTX to two patients (47), and they have not experienced CNS relapse. Thus, our cases indicate that a combination of the R-CHOP regimen and HD-MTX as CNS prophylaxis might be a reasonable treatment option for PAL.

In conclusion, PAL is a clinically aggressive disease, and its prognosis is usually poor. Considering that adrenal insufficiency is associated with worse outcomes, the awareness of adrenal insufficiency and the administration of an appropriate dose of hydrocortisone are important during the course of chemotherapy as well as at the initial manifestation of the disease. 
The authors state that they have no Conflict of Interest (COI).

\section{Acknowledgement}

The content of this article was announced in the 113th annual scientific meeting of the Japanese Society of Internal Medicine.

\section{References}

1. Freeman C, Berg JW, Cutler SJ. Occurrence and prognosis of extranodal lymphomas. Cancer 29: 252-260, 1972.

2. Mozos A, Ye H, Chuang WY, et al. Most primary adrenal lymphomas are diffuse large B-cell lymphomas with non-germinal center B-cell phenotype, BCL6 gene rearrangement and poor prognosis. Mod Pathol 22: 1210-1217, 2009.

3. Singh D, Kumar L, Sharma A, Vijayaraghavan M, Thulkar S, Tandon N. Adrenal involvement in non-Hodgkin's lymphoma: four cases and review of literature. Leuk Lymphoma 45: 789-794, 2004.

4. Rashidi A, Fisher SI. Primary adrenal lymphoma: a systematic review. Ann Hematol 92: 1583-1593, 2013.

5. A predictive model for aggressive non-Hodgkin's lymphoma. The International Non-Hodgkin's Lymphoma Prognostic Factors Project. N Engl J Med 329: 987-994, 1993.

6. Hans CP, Weisenburger DD, Greiner TC, et al. Confirmation of the molecular classification of diffuse large B-cell lymphoma by immunohistochemistry using a tissue microarray. Blood 103: 275282, 2004.

7. Ozimek A, Diebold J, Linke R, Heyn J, Hallfeldt K, Mussack T. Bilateral primary adrenal non-Hodgkin's lymphoma and primary adrenocortical carcinoma-review of the literature preoperative differentiation of adrenal tumors. Endocr J 55: 625-638, 2008.

8. Grigg AP, Connors JM. Primary adrenal lymphoma. Clin Lymphoma 4: 154-160, 2003.

9. Tumino S, Leotta ML, Branciforte G, Mantero F, Calogero AE. Bilateral adrenal non-Hodgkin lymphoma type B. J Endocrinol Invest 26: 1120-1123, 2003.

10. Kumar R, Xiu Y, Mavi A, El-Haddad G, Zhuang H, Alavi A. FDG-PET imaging in primary bilateral adrenal lymphoma: a case report and review of the literature. Clin Nucl Med 30: 222-230, 2005.

11. Seidenwurm DJ, Elmer EB, Kaplan LM, Williams EK, Morris DG, Hoffman AR. Metastases to the adrenal glands and the development of Addison's disease. Cancer 54: 552-557, 1984.

12. Redman BG, Pazdur R, Zingas AP, Loredo R. Prospective evaluation of adrenal insufficiency in patients with adrenal metastasis. Cancer 60: 103-107, 1987.

13. Hsu CW, Ho CL, Sheu WH, Harn HJ, Chao TY. Adrenal insufficiency caused by primary aggressive non-Hodgkin's lymphoma of bilateral adrenal glands: report of a case and literature review. Ann Hematol 78: 151-154, 1999.

14. Fukushima A, Okada Y, Tanikawa T, et al. Primary bilateral adrenal intravascular large B-cell lymphoma associated with adrenal failure. Intern Med 42: 609-614, 2003.

15. Kuwahara K, Fukata J, Kamio M, Mochizuki T, Tsuchiya A, Tanaka S. Angiotropic large cell lymphoma which infiltrated to the adrenal glands presenting as reversible adrenal insufficiency. Intern Med 37: 73-76, 1998.

16. Mah PM, Jenkins RC, Rostami-Hodjegan A, et al. Weight-related dosing, timing and monitoring hydrocortisone replacement therapy in patients with adrenal insufficiency. Clin Endocrinol (Oxf) 61: 367-375, 2004

17. Puar TH, Stikkelbroeck NM, Smans LC, Zelissen PM, Hermus AR. Adrenal crisis: still a deadly event in the 21st century. Am J Med 129: 339.e1-e9, 2016.

18. Cooper MS, Stewart PM. Corticosteroid insufficiency in acutely ill patients. N Engl J Med 348: 727-734, 2003.
19. Einaudi S, Bertorello N, Masera N, et al. Adrenal axis function after high-dose steroid therapy for childhood acute lymphoblastic leukemia. Pediatr Blood Cancer 50: 537-541, 2008.

20. Giorgino R. Pathophysiology of sympathoadrenal system. J Endocrinol Invest 11: 817-829, 1988.

21. Yanase T, Tajima T, Katabami $T$, et al. Diagnosis and treatment of adrenal insufficiency including adrenal crisis: a Japan Endocrine Society clinical practice guideline [Opinion]. Endocr J 63: 765784, 2016.

22. Habermann TM, Steensma DP. Lymphadenopathy. Mayo Clin Proc 75: 723-732, 2000 .

23. Pangalis GA, Vassilakopoulos TP, Boussiotis VA, Fessas P. Clinical approach to lymphadenopathy. Semin Oncol 20: 570-582, 1993.

24. Miyoshi T, Otsuka F, Suzuki J, et al. Abrupt enlargement of adrenal incidentaloma: a case of isolated adrenal metastasis. Endocr $\mathrm{J}$ 52: 785-788, 2005.

25. Mazzaglia PJ, Monchik JM. Limited value of adrenal biopsy in the evaluation of adrenal neoplasm: a decade of experience. Arch Surg 144: 465-470, 2009.

26. Welch TJ, Sheedy PF, Stephens DH, Johnson CM, Swensen SJ. Percutaneous adrenal biopsy: review of a 10-year experience. Radiology 193: 341-344, 1994.

27. Arellano RS, Harisinghani MG, Gervais DA, Hahn PF, Mueller PR. Image-guided percutaneous biopsy of the adrenal gland: review of indications, technique, and complications. Curr Probl Diagn Radiol 32: 3-10, 2003.

28. Casola G, Nicolet V, vanSonnenberg E, et al. Unsuspected pheochromocytoma: risk of blood-pressure alterations during percutaneous adrenal biopsy. Radiology 159: 733-735, 1986.

29. Coursin DB, Wood KE. Corticosteroid supplementation for adrenal insufficiency. JAMA 287: 236-240, 2002.

30. Dunnick NR, Korobkin M. Imaging of adrenal incidentalomas: current status. AJR Am J Roentgenol 179: 559-568, 2002.

31. Falchook FS, Allard JC. CT of primary adrenal lymphoma. J Comput Assist Tomogr 15: 1048-1050, 1991.

32. Young WF. Clinical practice. The incidentally discovered adrenal mass. N Engl J Med 356: 601-610, 2007.

33. Otsuka F, Ogura T, Nakagawa $M$, et al. Normotensive bilateral pheochromocytoma with Lindau disease: case report. Endocr J 43: 719-723, 1996.

34. Guo AC, Cummings TJ, Dash RC, Provenzale JM. Lymphomas and high-grade astrocytomas: comparison of water diffusibility and histologic characteristics. Radiology 224: 177-183, 2002.

35. Kim YR, Kim JS, Min YH, et al. Prognostic factors in primary diffuse large B-cell lymphoma of adrenal gland treated with rituximab-CHOP chemotherapy from the Consortium for Improving Survival of Lymphoma (CISL). J Hematol Oncol 5: 49, 2012.

36. Miyazaki K, Yamaguchi M, Suzuki R, et al. CD5-positive diffuse large B-cell lymphoma: a retrospective study in 337 patients treated by chemotherapy with or without rituximab. Ann Oncol 22: 1601-1607, 2011.

37. Ennishi D, Takeuchi K, Yokoyama M, et al. CD5 expression is potentially predictive of poor outcome among biomarkers in patients with diffuse large B-cell lymphoma receiving rituximab plus CHOP therapy. Ann Oncol 19: 1921-1926, 2008.

38. Ichikawa $S$, Fukuhara N, Inoue A, et al. Clinicopathological analysis of primary adrenal diffuse large B-cell lymphoma: effectiveness of rituximab-containing chemotherapy including central nervous system prophylaxis. Exp Hematol Oncol 2: 19, 2013.

39. Ide M, Fukushima N, Hisatomi T, et al. Non-germinal cell phenotype and bcl-2 expression in primary adrenal diffuse large B-cell lymphoma. Leuk Lymphoma 48: 2244-2246, 2007.

40. Rosenwald A, Wright G, Chan WC, et al. The use of molecular profiling to predict survival after chemotherapy for diffuse largeB-cell lymphoma. N Engl J Med 346: 1937-1947, 2002. 
41. Kridel R, Dietrich PY. Prevention of CNS relapse in diffuse large B-cell lymphoma. Lancet Oncol 12: 1258-1266, 2011.

42. Villa D, Connors JM, Sehn LH, Gascoyne RD, Savage KJ. Diffuse large B-cell lymphoma with involvement of the kidney: outcome and risk of central nervous system relapse. Haematologica 96: 1002-1007, 2011

43. Mermershtain W, Liel Y, Zirkin HJ, Lupu L, Lantsberg S, Cohen Y. Primary bilateral adrenal lymphoma relapsing as a solid cerebral mass after complete clinical remission: a case report. Am J Clin Oncol 24: 583-585, 2001.

44. Abramson JS, Hellmann M, Barnes JA, et al. Intravenous methotrexate as central nervous system (CNS) prophylaxis is associated with a low risk of CNS recurrence in high-risk patients with diffuse large B-cell lymphoma. Cancer 116: 4283-4290, 2010.
45. Tomita N, Yokoyama M, Yamamoto W, et al. Central nervous system event in patients with diffuse large B-cell lymphoma in the rituximab era. Cancer Sci 103: 245-251, 2012.

46. Cheah CY, Herbert KE, O'Rourke K, et al. A multicentre retrospective comparison of central nervous system prophylaxis strategies among patients with high-risk diffuse large B-cell lymphoma. Br J Cancer 111: 1072-1079, 2014.

47. Allolio B, Fassnacht M. Clinical review: adrenocortical carcinoma: clinical update. J Clin Endocrinol Metab 91: 2027-2037, 2006.

The Internal Medicine is an Open Access article distributed under the Creative Commons Attribution-NonCommercial-NoDerivatives 4.0 International License. To view the details of this license, please visit (https://creativecommons.org/licenses/ by-nc-nd/4.0/).

(C) 2017 The Japanese Society of Internal Medicine Intern Med 56: 2261-2269, 2017 